- Dental instruments such as endodontic reamers that are difficult to clean and should be considered as single use.

- Manual cleaning of dental instruments has a risk of puncture wounds, lacerations and cuts.

- Ultrasonic cleaners clean well, but the ultrasonic solution can become contaminated with debris.

- Washer disinfectors provide fully automated and validated cleaning but have yet to be taken up in large numbers of dental practices.

- Detailed cleaning instructions are required from instrument and washer disinfector manufacturers.

\title{
Cleanability of dental instruments - implications of residual protein and risks from Creutzfeldt-Jakob disease
}

\author{
J. T. Walker, ${ }_{1}^{1}$ J. Dickinson, ${ }^{2}$ J. M. Sutton, ${ }_{1}^{3}$ N. D. H. Raven ${ }^{4}$ and P. D. Marsh ${ }^{5}$
}

Cleaning of dental instruments is the first line of control in reducing the adherent bioburden. The threat of vCJD and the difficulty in removing prion protein has provided a new challenge for cleaning surgical and dental instruments. Prion proteins are also more resistant to many disinfection and sterilisation techniques. A number of different methods are currently available in primary care for cleaning instruments including manual washing, ultrasonic cleaners and washer disinfectors. Manual cleaning of dental instruments is time-consuming, introduces operator error and the risk of puncture wounds, is not reproducible and does not completely remove debris from instruments. Ultrasonic baths are significantly more effective than hand cleaning alone and are currently used by the majority of dental surgeries (often as an adjunct to manual cleaning). Automated washer-disinfectors appear to provide a validated, reliable and reproducible procedure for disinfection and sterilisation of dental instruments to ensure both the safety of patients and dental staff. Dental instruments that are difficult to clean are frequently contaminated with tissue debris after routine reprocessing and cannot be excluded as a potential transmission risk for infectious agents, including prions. The transmission of VCJD via dentistry is considered to be low risk, however, the Department of Health (DoH) has recently advised dentists to ensure that endodontic reamers and files are treated as single-use as a precautionary basis in order to further reduce any risk of vCJD transmission.

\section{INTRODUCTION}

Approximately 44 million claims are made annually for the provision of NHS dental treatment in the UK. ${ }^{1}$ The mouth is known to contain a wide range of microorganisms such as fungi, bacteria and viruses, and so effective procedures to prevent crossinfection between dentists, dental staff

${ }^{*}$-5 HPA Centre for Emergency Preparedness and Response, Porton Down, Salisbury, SP4 0JG; ${ }^{5(a \text { aso })}$ Leeds Dental Institute, Leeds, LS2 9LU

${ }^{*}$ Correspondence to: Dr Jimmy Walker

Email:jimmy.walker@hpa.org.uk

\section{Refereed Paper}

Accepted 15 May 2007

DOI: $10.1038 /$ bdj.2007.893

${ }^{\circ}$ British Dental Journal 2007; 203: 395-401 and patients are essential. ${ }^{2}$ However, the emergence in the United Kingdom in the mid-1990s of variant Creutzfeldt-Jakob Disease (vCJD), linked to the consumption of bovine spongiform encephalopathy (BSE)-tainted meat products, has raised concerns of the risks related to the inadequate cleaning and sterilisation of instruments in dentistry prior to their reuse on patients. The biochemical marker of prion disease $\left(\mathrm{PrP}^{\mathrm{Sc}}\right)$ is protease- and heatresistant, and binds strongly to stainless steel, and, therefore, is difficult to remove from surgical instruments by routine cleaning. There is limited information on the presence of prion proteins in human oral tissues. Studies using animal models have shown the disease-associated prion to be located in the trigeminal ganglion, pulpal tissue and gingival tissue in a hamster model ${ }^{3}$ and tongue in a transmissible mink encephalopathy model. ${ }^{4,5}$ It is difficult to extrapolate these findings directly to humans because of obvious species differences and the differences between vCJD and the prion strains used for these studies. In humans, post-mortem studies of vCJD tissues ${ }^{6}$ have shown that abnormal protein is accumulated in the CNS, ${ }^{7}$ peripheral nerves and trigeminal ganglia, ${ }^{8}$ ocular $^{9}$ and lymphoreticular tissues, including tonsils, spleen ${ }^{10}$ and appendix. ${ }^{8}$ In the oral cavity, the largest collection of lymphoid tissues is located in the submucous tissue of the lingual tonsil ie posterior third of the tongue, which is rarely traumatised during routine dental procedures. Peripheral nerves 
may be contacted more routinely, particularly during certain types of operation (eg endodontic treatment). The limited amount of data currently available on the presence of $\mathrm{PrP}^{\mathrm{Sc}}$ in oral tissues from vCJD patients ${ }^{11}$ implies that these tissues are negative. As dental instruments have the potential to come into contact with a range of oral tissues that may carry vCJD infectivity, particularly peripheral nerves and lymphoid tissue, it seems prudent on a precautionary basis to use the most effective instrument cleaning and sterilisation approaches to control this risk, especially as relatively high levels of infectivity may be present in tissues early in the disease incubation period, before clinical symptoms are observed.

Since 1993 more than 80 cases of CJD have been recognised 1.6-17 years after neurosurgical placement of grafts of human cadaver dura mater. ${ }^{12}$ For dental professionals there is the concern in using human dura mater material in procedures outside the central nervous system, for example, in periodontal regeneration techniques. ${ }^{13}$ Although epidemiological studies have not indicated a correlation of vCJD cases with dentistry, there have been suggested links in two small CJD disease clusters. ${ }^{14,15}$

\section{Fouling of surgical instruments}

The Oxford English Dictionary defines clean as 'free from dirt'. The ISO 15883 part 1 defines clean as the extent necessary for its subsequent reprocessing - however, these definitions are of little practical value as the minimum safe level of residual soil/protein is unknown. To compound this problem, the exact nature of the residual soil on an instrument is also largely unknown and may vary depending on the use to which the instrument is subjected and where in the body the instrument has been used.

Following use, dental instruments can be grossly fouled with oral tissues and secretions such as blood, saliva etc (Figs 1a-b), and restorative material, all of which may contain infectious material. By their very nature such grossly fouled dental instruments can be difficult to clean. ${ }^{16}$ Gross contamination of medical instruments by blood, saliva and dental tissue may also impair the sterilisation process by insulating blood borne pathogens and viruses. ${ }^{17}$

In a study to qualitatively and quantitatively assess bacterial and fungal contamination from three different types of used burs for cavity preparation the microbial count ranged from 0 to $6.92 \times 10^{4}$ CFU.ml ${ }^{-1} .{ }^{18}$ The species of bacteria and fungi recovered from the burs included examples of the following, Streptococcus spp., Lactobacillus spp., Staphylococcus spp., black pigmented anaerobes and fungi eg Candida. Therefore, it is clear that validated methods of cleaning are urgently required.

Whilst it has been shown that the cleaning of re-usable dental instruments is undertaken using poorly controlled processes and procedures ${ }^{19}$ there is an obvious reliance on the use of autoclaving to completely eliminate the possibility of microbial cross infection.

Also, new endodontic files received from the manufacturer would be expected to be sterile, however, in one survey of 150 newly supplied files, 13\% were found to be positive for microbial culture. $^{20}$ This may suggest that unless manufacturers can provide sterility assurance, perhaps endodontic files should be sterilised prior to use.

Endodontic files are used in dental procedures involved in the maintenance of dental pulp and the treatment of the pulp cavity that includes blood ${ }^{21}$ and peripheral nerve tissue known to carry vCJD. Endodontic files have an intricate surface topography with a very high surface area to volume ratio due to their small size and serrated edges. These intricate surfaces are able to trap protein which is tenaciously attached to the surface through subsequent autoclaving cycles. ${ }^{22}$

A recent study of instruments submitted from general dental practitioners and a dental hospital showed that 76\% of instruments from dental practice and 14\% from dental hospitals demonstrated a significant degree of visible gross contamination on supposedly 'decontaminated' endodontic files (Table 1). ${ }^{23}$ Residual protein was found on all the endodontic files examined regardless of the cleaning process, with a median value of $5.4 \mu \mathrm{g}$ (range 0.5-63.2 $\mu \mathrm{g}$ ). ${ }^{23}$ Although there have been no data on vCJD infectivity in dental pulp it may be reasonable to assume that the dental pulp of individuals subclinically-infected with vCJD may be infectious, with the caveat that the level of infectivity remains unknown. ${ }^{24}$ Therefore if prions, which are resistant to sterilisation techniques currently used in dental practice, were present, they could be irreversibly bound and transmitted via the stainless steel surface of the endodontic file. ${ }^{25}$

As a result, in a recent communication Advice for dentists on re-use of endodontic instruments and variant Creutzfeldt-Jakob Disease ( $v$ CJD), the DoH has advised dentists to ensure that endodontic reamers and files are treated as single use as a precaution in order to reduce any risk of vCJD transmission. ${ }^{26}$

\section{Resistance of prion protein}

The failure to remove protein and other tissue debris from surgical instruments would be academic if routine cleaning and sterilisation processes were effective at rendering this material non-infectious. Sadly this is not the case as, for example, prion agents which show binding to surgical steel ${ }^{25}$ become more resistant to inactivation processes when dried onto such surfaces, ${ }^{27,28}$ and have been shown to transmit disease experimentally ${ }^{25}$ and clinically, even after some disinfection. ${ }^{29}$ Transmissible Spongiform Encephalopathies (TSE) agents are at best only partially inactivated using the sterilisation techniques currently available in primary dental care as they are far more resistant to physical and chemical inactivation than conventional pathogens. ${ }^{30}$ WHO guidelines suggest the use of (a) immersion in sodium hypochlorite (20,000 ppm available chlorine) for one hour, (b) boiling in $1 \mathrm{M}$ sodium hydroxide for one hour, or (c) vacuum autoclaving at $121^{\circ} \mathrm{C}$ for $30-90$ minutes in the presence of $2 \mathrm{M}$ sodium hydroxide $\mathrm{e}^{31-33}$ for the inactivation of prions. Such procedures are inappropriate for surgical or dental instruments due to degradation and tarnishing of the metal surface, hazards to the user and issues with disposal.

Whilst a number of studies have developed procedures for prion inactivation, ${ }^{25,28,34-37}$ many of these are not yet available for the sterilisation of dental instruments because they are still at the developmental stage. Whichever of these methods finally translates into routine use in dental practice for TSE agent inactivation, gross removal of protein and tissue remains paramount in ensuring that any sterilisation technique is fully effective.

\section{METHODS OF CLEANING INSTRUMENTS}

According to ISO 17664:2004, manufacturers are now required to provide 
Table 1 Results of various cleaning methods to remove debris from dental instruments

\begin{tabular}{|c|c|c|c|c|}
\hline \multirow[t]{2}{*}{ Instrument type } & \multicolumn{4}{|c|}{$\begin{array}{l}\text { Percentage of instruments exhibiting significant levels of gross } \\
\text { contamination or containing blood following reprocessing }\end{array}$} \\
\hline & Manual & Ultrasonic & CSSD & References \\
\hline Siqveland Bands & $34 \% B$ & $6 \% B$ & - & 41 \\
\hline Siqveland Retainers & $32 \% B$ & $3 \% B$ & - & 40 \\
\hline Endodontic files & $76 \%{ }^{*}$ & - & - & 23 \\
\hline Endodontic files & $98 \% *$ & - & - & 22 \\
\hline $\begin{array}{l}\text { Surgical instruments } \\
\text { - artery forceps }\end{array}$ & - & - & 64 & 83 \\
\hline Orthodontic files & - & - & - & 61 \\
\hline Endoscope & $\begin{array}{l}1.3 \times 105 \\
\text { CFU.ml }\left.\right|^{-1} \text { residual }\end{array}$ & - & - & 84 \\
\hline
\end{tabular}

instructions for the decontamination of their instruments and equipment for medical professionals to follow. There does appear to be a requirement for clear and unambiguous advice to be provided to the dental team undertaking these important cleaning procedures, which are critically important for patient safety, and to drive forward improvements in cleaning. ${ }^{19}$

The BDA recommends that all instruments contaminated with oral fluids must be thoroughly cleaned and sterilised after use and has identified three stages to the decontamination process: $:^{38}$ pre-sterilisation cleaning, sterilisation and storage. In essence, the decontamination process should be looked at as a holistic approach and not as individual components.

The BDA also advises that: i) ultrasonic cleaners and washer/disinfectors are preferred over hand cleaning of instruments, and ii) that automated cleaning is preferred to manual cleaning, ensuring reproducibility and control of the process. ${ }^{38}$ Experimental results that support these recommendations and discussion of the issues related to manual washing, ultrasonic cleaners and washer disinfectors, are discussed below, together with some details of new approaches.

\section{Manual cleaning}

Manual cleaning has been reported to be used by $91 \%$ and $96 \%$ of general dental practitioners in two recent surveys of decontamination practices used in Scotland and the rest of the UK, respectively. ${ }^{19,39}$ Manual cleaning is obviously a difficult task to undertake efficiently due to the complex surface contours of steel burs, matrix bands and endodontic files. A study of general dental practices demonstrated that $76 \%$ of endodontic files cleaned by hand-brushing prior to autoclaving were still heavily contaminated. ${ }^{23}$ Similarly, a study of Siqveland matrix bands and retainers submitted from 16 dental practices indicated that $53 \%$ of them were hand-scrubbed prior to sterilisation and that $34 \%$ of bands and $32 \%$ of hand scrubbed retainers were positive for residual blood (Table 1). ${ }^{40,41}$ Manual cleaning of dental instruments is subjective and not reproducible, with variations in the type of detergent, water temperature, brush type, number and strength of strokes used in the cleaning process, with little opportunity for control or validation. There appears to be no standardisation of concentration or type of cleaning agents in GDPs, with 69\% using a cleaning agent other than water of which only $2 \%$ used a proprietary detergent formulated for manual washing of surgical instruments. ${ }^{19}$ In addition, items such as turbines, hand-pieces and their attachments that are used in the mouth are difficult to clean manually due to the presence of narrow lumens, deep recesses and cavities. The judgement as to whether a handcleaned dental instrument is clean is also subjective and there is no validation to indicate that satisfactory cleanliness has actually been achieved. ${ }^{42}$ Separate sink areas should also be used for instrument cleaning but it has been found that the same sink was used by GDP staff for hand cleaning (84\%) and beverage preparation $(16 \%) .{ }^{19}$ Even though routine glove wearing has increased to 96-99\%, there is the danger of puncture wounds, lacerations and cuts whilst hand cleaning dental instruments (particularly doubleended instruments) and the consequent risk of cross-infection. ${ }^{19,41,43}$

\section{Ultrasonic cleaners}

Ultrasonic cleaning consists of immersing the instrument in a detergent fluid that is then subjected to a series of high frequency sound waves which result in local regions of alternating high and low pressure. ${ }^{44}$ Thousands of vapour bubbles form under low pressure that burst at high pressure creating vigorous cavitation that cleans surfaces and inside crevices. Ultrasonic cleaning was reported to have been used by 7\% of respondents in a survey of decontamination practices used by UK general dental practitioners. ${ }^{39}$ More recently 92\% of surgeries were reported to have an ultrasonic bath. ${ }^{19} \mathrm{~A}$ recent study of instruments from a dental hospital demonstrated that $14 \%$ of endodontic files immersed in a proprietary detergent agent within an ultrasonic bath for six minutes prior to autoclaving were still heavily contaminated. ${ }^{23}$ There are a number of commonly used dental instruments that have recesses and complex shapes or patterns, and are therefore preferably decontaminated using ultrasonic cleaning prior to autoclaving. Ultrasonic cleaners should contain a detergent capable of lowering surface tension that would promote emulsification of fatty material and dispersal of protein aggregates (as distinct from a disinfectant). The ultrasonic solution can become contaminated with debris after successive uses and it is recommended to thoroughly rinse instruments after sonication. ${ }^{45}$ The detergent should 
be run to waste at the end of each clinical session (or changed at not more than four-hourly intervals) and must be emptied at the end of each day. ${ }^{38,46,47}$ However, in one study, only $63 \%$ of surgeries emptied the ultrasonic bath at the end of the working day and in 11\% of surgeries the interval was found to be five or more days. ${ }^{19}$ Guidelines for the operation and maintenance of ultrasonic cleaners are cited in HTM2030 (currently being superseded by HTM 01-01). ${ }^{48}$ In practice, it has been found that only $4 \%$ of surgeries check the efficacy of their ultrasonic cleaning by means of the aluminium foil erosion test. ${ }^{19}$

\section{Washer disinfector}

According to the current Medical Device Directive, validated procedures must be used for cleaning, disinfection and sterilisation of medical devices to ensure reliable and reproducible processing results as well as for the safety of patients, users and third parties. ${ }^{49}$ Hence, there is now increased emphasis on the washing and thermal disinfection stages of the process, so that instruments are physically clean before sterilisation, while manual cleaning of medical devices is discouraged. ${ }^{50}$ Washer-disinfectors are generally considered to be the safest method for reprocessing medical devices and consists of various automated stages (pre-rinsing, cleaning, interim rinsing, thermal disinfection and final rinsing as well as possibly drying). Washer disinfectors need to be constructed according to ISO 15883 part 1 and need to be compliant with and installed, commissioned, validated, maintained, serviced, monitored and periodically tested to HTM 2030 guidelines (currently being superseded by HTM 01-01). ${ }^{48}$

During a recent survey, none of 167 surgeries taking part used a washer disinfector as a method of cleaning instruments, ${ }^{19}$ hence, information on their efficacy in general dental practice is as yet limited.

A number of studies have examined washer-disinfectors for cleaning medical instruments such as flexible endoscopes and shown that automated cleaning produces better results than manual methods..$^{51}$ The type of cleaning agent appears to play an important role in the efficacy of the cleaning process. ${ }^{52}$ In some cases the use of particular cleaning agents did not meet the criteria necessary for either

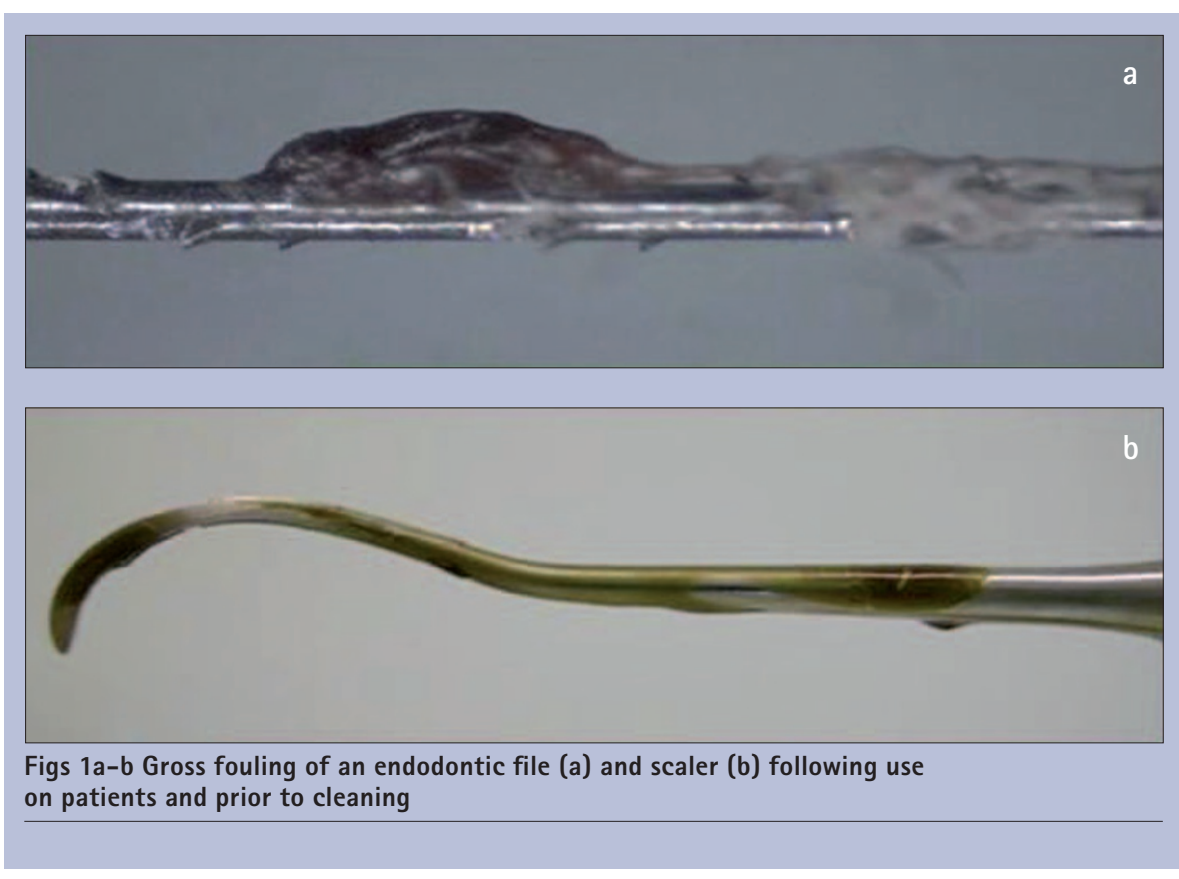

visible cleaning or for a 99.9\% reduction in bacterial load. ${ }^{53-55}$ In addition various studies of outbreaks have shown that the water used for the rinse water can become contaminated with Pseudomonas aeruginosa that colonised the interior surfaces and formed a biofilm..$^{56-}$ ${ }^{59}$ The guidelines indicate that the final rinse water used in a washer disinfector must not present a microbiological hazard and that there should be no recovery of microorganisms from the final rinse water. ${ }^{48}$ In addition, cleaning agents are also regulated by the same guidelines and should be validated before use. ${ }^{48}$

An investigation into decontamination methods has found that it was not possible to clean assembled Siqveland matrix bands using either a washer disinfector or an instrument washer ${ }^{60}$ and recommended that matrix bands should be single use only. The authors also indicated that the use of a pre-soaking step using an enzymatic agent enhances the effectiveness of the pre-sterilisation cleaning process and that only the retainers should then be processed in an instrument washer. ${ }^{60}$

Novel methods suitable for cleaning dental instruments

Effective cleaning technologies should have a number of common features in that they should have excellent penetrative power, be simple to use, be cost effective and provide confidence that disinfection has been carried out. A number of novel cleaning methods

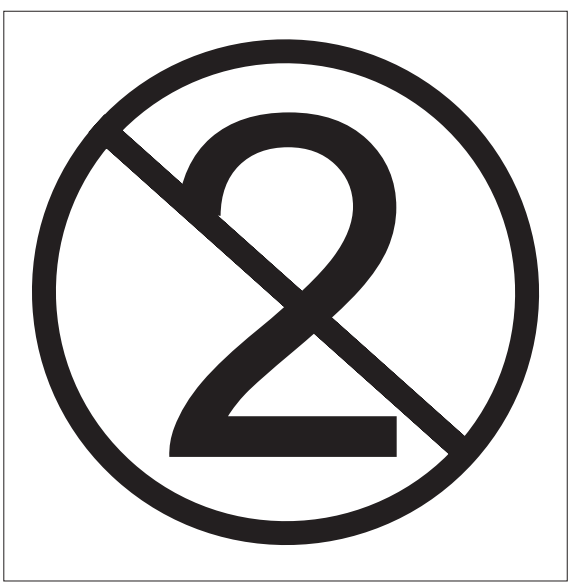

Fig. 2 Single use symbol as used on packaging of instruments intended for single use

are currently being developed, particularly in response to concerns over the presence of thermally resistant prions, some of which, eg radiofrequency (RF) - generated gas plasma - are still at the developmental stage and others, such as gaseous ozone technology and a number of chemical technologies, are currently available commercially for sterilisation of surgical instruments.

Radiofrequency (RF) - generated gas plasma. Radiofrequency (RF) - generated gas plasma is well established for the low temperature $\left(30^{\circ} \mathrm{C}\right)$ elimination of organic material from surfaces, eg from the solvent-free removal of machine oils to the removal of organic polymers from delicate electronic components. ${ }^{61}$ Plasma leaves no residue and does not produce any toxic products, typically generating only $\mathrm{CO}_{2}, \mathrm{H}_{2} \mathrm{O}$ and $\mathrm{N}_{2}$ as a gaseous 
waste. ${ }^{62}$ It has been used previously for the sterilisation of chemical and biological warfare agents ${ }^{63,64}$ and also for the disinfection of surgical and dental instruments. ${ }^{65-67}$ Plasma-based ultraviolet irradiation has been used for the inactivation of Staphylococcus aureus on dental handpieces and orthodontic forceps, although that particular study did not assess whether the instruments were actually clean after treatment. ${ }^{68}$ In terms of cleaning instruments and reducing TSE infectivity, recent studies have used scanning electron microscopy (SEM) to visualise endodontic files before and after plasma treatment. In all cases, the amount of organic material was not only reduced to a level below the detection limit of the assay technique but also eliminated the transmission of TSE infectivity. ${ }^{37,62,69}$ Although still at the experimental stage, this technology is showing real promise and could be available for use within five years.

Ozone. Ozonation has been used for a number of years to disinfect water and a range of commercial uses have been found for ozone including disinfection of bottled water, swimming pools, prevention of fouling of cooling towers, and wastewater treatment. ${ }^{70-72}$ Ozone $\left(\mathrm{O}_{3}\right)$ is a low molecular-weight gaseous molecule composed of three oxygen atoms which at room temperature, decomposes rapidly to oxygen. Ozone has a characteristic odour, often described as similar to 'fresh air after a thunderstorm'. ${ }^{73}$ Ultraviolet radiation (188 $\mathrm{nm}$ wavelength) and corona discharge can be used to initiate free radical formation, thereby generating ozone. ${ }^{70}$ The bacteriocidal effects of ozone have been studied on a wide variety of organisms, including Gram-positive and Gram-negative bacteria as well as spores and vegetative cells and has been found to destroy microorganisms by the progressive oxidation of the cell surface. ${ }^{74-77}$ As discussed, ozone has traditionally been used for microbial control in a range of environments. More recently ozone has been developed for the sterilisation of heat sensitive materials including medical devices and narrow lumen devices ${ }^{78}$ and is currently being used to investigate the sterilisation of medical instruments that have been contaminated by prions (263K scrapie). This novel approach is still at an early stage but may prove useful in the elimination of TSE infectivity and sterilisation of heat-sensitive medical instruments and/or lumens.

Chemical technologies. There are a number of products independently certified for use by a European Community Notified Body (CE Marked) (eg Hamo ${ }^{\text {тм }}$ 100 Prion Inactivating Detergent - www. steris.com, Prionzyme- $\mathrm{M}^{\mathrm{TM}}$ - www.genencor.com, RelyOn ${ }^{\mathrm{TM}}$ - www.relyon.dupont. com) that have been shown to reduce the levels of prion infectivity, ${ }^{34,36,79}$ their use remains at the discretion of individual users, subject to local or national restrictions. The above products operate under relatively mild alkaline conditions, which clearly represent an improvement in terms of instrument damage and user/environmental safety over existing recommended conditions. Whilst other agents have also been shown to exert potent prion-decontaminating activities, either based on alkaline cleaning, peracetic acid treatment or enzymic procedures, they have not yet achieved CE Mark. ${ }^{80}$ Further research is required to assess the suitability of these techniques for their routine application in general dental practice.

\section{ISSUES OF REPROCESSING \\ VERSUS SINGLE USE}

A number of intra-oral items eg dams, some burs, hypodermic needles, scalpels and blades, are available as single use, and should be immediately disposed of as clinical waste after use. ${ }^{81}$ There should never be any attempt to reprocess these items. It has recently been demonstrated that $74 \%$ of dental nurses and 54\% of dentists do not understand the symbol for 'single use' (Fig. 2) and that 15\% of GDPs permitted re-use of single use instruments. ${ }^{19}$ Key factors in preventing single-use instruments from re-entering the practice include enhanced labelling as well as education and training of dental staff to raise awareness of these issues.

From the personal experience of the authors, it is clear that many re-sterilisable medical devices, ie re-usable dental instruments, are either supplied with inadequate or no cleaning instructions from the manufacturer, despite this now being part of ISO 17664:2004. The Medical Devices Directive requires manufacturers of dental instruments to provide validated reprocessing instructions including information on appropriate cleaning, disinfecting, and packaging and where appropriate re-sterilisation to allow re-use of the device.
The recent guidelines from the $\mathrm{DoH}$ insists that manufacturers' decontamination instructions are followed for all instruments. ${ }^{26}$ Nevertheless, re-use of devices labelled by the manufacturer as single-use or failure to follow the manufacturers instructions may render the practitioner vulnerable to legal action or a charge of professional misconduct.

The emergence of vCJD has provided cross-infection control specialists with a new challenge. The current Department of Health (DoH) risk assessment categorises dentistry as 'low risk' for potential transmission of vCJD. ${ }^{82}$ The report comments that the possibility of infectivity in dental pulpal tissue cannot be ruled out and recognises that endodontic files, ie the instruments coming in direct contact with the pulp, are particularly difficult to clean. Endodontic files are regularly found to be contaminated with residual tissue after reprocessing and, as such, cannot be excluded as a potential risk of transmitting infectious agents. Furthermore, depending on the type of file design and decontamination procedure performed, a reduction of 23\% in the cutting efficiency of endodontic files has been found after decontamination. ${ }^{83}$ The DoH risk assessment assumes that optimal reprocessing standards are observed but these validated processes are as yet not in place across primary health-care establishments and so further guidelines, indicating that the highest standards of decontamination are to be observed for all dental instruments, have recently been published. ${ }^{26}$

In summary, there is clear evidence that manual cleaning of dental instruments is not controllable or reproducible and does not remove debris from dental instruments. ${ }^{40,41}$ The emergence of vCJD, which is heat-resistant and binds strongly to stainless steel, has raised concerns of the risks related to the inadequate cleaning and sterilisation of instruments in dentistry prior to their re-use on patients. Used optimally, ultrasonic baths are significantly more effective than hand cleaning and are currently used by the majority of dental surgeries. ${ }^{19}$ Automated washer-disinfectors may provide the ideal mechanism for cleaning dental instruments but have not yet been widely taken up by the dental profession on an individual practice basis. The reason for this poor uptake may primarily be the costs involved 
in the purchase of washer disinfectors and the continued and ongoing validation and monitoring of the equipment that is required. The current practice in hospitals is to use Central Sterile Services Departments (CSSD) and this may be an approach for the dental profession in the long term. Gas plasma generators are also being investigated but it is too early to envisage how these would be implemented within the dental profession although there does not seem to be much doubt about the effectiveness of the equipment and processes.

Some instruments such as endodontic files are inherently difficult to clean and may come into contact with peripheral nerves known to carry vCJD. Hence, the provision of clear and unambiguous advice to dentists from the Department of Health in a communication Advice for dentists on re-use of endodontic instruments and variant Creutzfeldt-Jakob Disease ( $v C J D$ ) will ensure that endodontic reamers and files are treated as single use to further reduce any risk of vCJD transmission through dentistry. ${ }^{26}$

The views expressed are those of the authors and not necessarily those of the Department of Health, UK. This manuscript is dedicated to the late Dr Andrew Robinson, a respected colleague and good friend.

1. Dental Practice Board. Annual review. London: The Stationary Office, 1999.

2. Miller $\mathrm{C} \mathrm{H}$, Tan C M, Beiswanger M A et al. Cleaning dental instruments: measuring the effectiveness of an instrument washer/disinfector. Am J Dent 2000; 13: 39-43.

3. Ingrosso L, Pisani F, Pocchiari M. Transmission of the $263 \mathrm{~K}$ scrapie strain by the dental route. J Gen Virol 1999; 80: 3043-3047.

4. Bartz J C, Kincaid A E, Bessen R A. Rapid prion neuroinvasion following tongue infection. J Virol 2003; 77: 583-591.

5. Mulcahy E R, Bartz J C, Kincaid A E, Bessen R A. Prion infection of skeletal muscle cells and papillae in the tongue. J Virol2004; 78: 6792-6798.

6. Collins S, Boyd A, Fletcher A et al. Recent advances in the pre-mortem diagnosis of Creutzfeldt-Jakob disease. J Clin Neurosci 2000; 7: 195-202.

7. Wadsworth J D, Joiner S, Hill A F et al. Tissue distribution of protease resistant prion protein in variant Creutzfeldt-Jakob disease using a highly sensitive immunoblotting assay. Lancet 2001; 358: 171-180.

8. Head M W, Ritchie D, Smith N et al. Peripheral tissue involvement in sporadic, iatrogenic, and variant Creutzfeldt-Jakob disease: an immunohistochemical, quantitative, and biochemical study. Am J Pathol 2004; 164: 143-153.

9. Head M W, Northcott V, Rennison K et al. Prion protein accumulation in eyes of patients with sporadic and variant Creutzfeldt-Jakob disease. Invest Ophthalmol Vis Sci 2003; 44: 342-346.

10 Bruce M E, McConnell I, Will R G, Ironside J W. Detection of variant Creutzfeldt-Jakob disease infectivity in extraneural tissues. Lancet 2001; 358: 208-209.

11. Head M W, Ritchie D, McLoughlin V, Ironside J W. Investigation of PrPres in dental tissues in variant CJD. Br Dent J 2003; 195: 339-443.
12. Brown $P$, Preece $M$, Brandel J P et al. latrogenic Creutzfeldt-Jakob disease at the millennium. Neurology 2000; 55: 1075-1081.

13. Bartolucci E G. A clinical evaluation of freezedried homologous dura mater as a periodontal free graft material. Study in humans. J Periodontol 1981; 52: 354-361.

14. Will R, Matthews W. Evidence for case-to-case transmission of Creutzfeldt-Jakob disease. J Neurol Neurosurg Psychiatry 1982; 45: 235-238.

15. Arakawa K, Nagara H, Itoyama Y et al. Clustering of three cases of Creutzfeldt-Jakob disease near Fukuoka City, Japan. Acta Neurol Scand 1991; 84: 445-447.

16. Murdoch H, Dickinson J, Walker J T et al. Surface decontamination of surgical instruments: an ongoing dilemma. J Hosp Infect 2006; 63: 432-438.

17. Miller C. Instrument cleaning involves multiple steps. Dentist 1990; 68: 23-25.

18. Whitworth C L, Martin M V, Gallagher M, Worthington $\mathrm{HV}$. A comparison of decontamination methods used for dental burs. Br Dent J 2004; 197: 635-640.

19. Bagg J, Smith A J, Hurrell D, McHugh S, Irvine G. Pre-sterilisation cleaning of re-usable instruments in general dental practice. Br Dent J 2007; 202: E22.

20. Roth TP, Whitney S I, Walker S G, Friedman S. Microbial contamination of endodontic files received from the manufacturer. J Endod 2006: 32: 649-651.

21. Wroe S J, Pal S, Siddique D et al. Clinical presentation and pre-mortem diagnosis of variant Creutzfeldt-Jakob disease associated with blood transfusion: a case report. Lancet 2006; 368: 2061-2067.

22. Smith A, Letters $S$, Lange $A$ et al. Residual protein levels on reprocessed dental instruments. J Hosp Infect 2005; 61: 237-241.

23. Smith A, Dickson M, Aitken J, Bagg J. Contaminated dental instruments. J Hosp Infect 2002; 51: 233-235.

24. Spongiform Encephalopathy Advisory Committee. Position statement VCJD and endodontic dentistry. 2006. http://www.seac.gov.uk/statements/ state-vcjd-dentrstry.htm (accessed 23 April 2007).

25. Zobeley E, Flechsig E, Cozzio A, Enari M, Weissmann C. Infectivity of scrapie prions bound to a stainless steel surface. Mol Med 1999; 5: 240-243

26. Department of Health. Advice for dentists on re-use of endodontic instruments and variant Creutzfeldt-Jakob Disease (vCJD). 2007. http:// www.dh.gov.uk/en/Publicationsandstatistics/Lettersandcirculars/Dearcolleagueletters/DH_074001 (accessed 23 April 2007)

27. Taylor D. Exposure to, and inactivation of the unconventional agents that cause transmissible degenerative encephalopathies. In Baker H, Ridley $\mathrm{R}(\mathrm{ed})$. Prion diseases. pp 105-118. Totowa, NJ: Human Press, 1996.

28. Peretz D, Supattapone S, Giles K et al. Inactivation of prions by acidic sodium dodecyl sulfate. J Virol 2006; 80: 322-331.

29. Bernoulli C, Siegfried J, Baumgartner $G$ et al. Danger of accidental person-to-person transmission of Creutzfeldt-Jakob disease by surgery. Lancet 1977: 1: 478-479.

30. Gill D S, Tredwin C J, Gill S K, Ironside J W. The transmissible spongiform encephalopathies (prion diseases): a review for dental surgeons. Int Dent J 2001; 51: 439-446.

31. World Health Organization. General considerations for effective TSE agent decontamination in healthcare settings. Geneva: World Health Organization, 1999. http://www.who.int/entity/ csr/resources/publications/bse/whocdscsraph2003.pdf (Accessed 23 April 2007)

32. Taylor D M. Resistance of transmissible spongiform encephalopathy agents to decontamination. Contrib Microbio/ 2004; 11: 136-145.

33. Taylor D M. Inactivation of transmissible degenerative encephalopathy agents: a review. Vet J 2000; 159: 10-17.

34. Fichet G, Comoy E, Duval C et al. Novel methods for disinfection of prion-contaminated medical devices. Lancet 2004; 364: 521-526.

35. Yan Z X, Stitz L, Heeg P, Pfaff E, Roth K. Infectivity of prion protein bound to stainless steel wires: a model for testing decontamination procedures for transmissible spongiform encephalopathies. Infect Cont Hosp Epidemio/ 2004; 25: 280-283.

36. Jackson G S, McKintosh E, Flechsig E et al. An enzyme-detergent method for effective prion decontamination of surgical steel. J Gen Virol 2005; 86: 869-878.

37. Baxter H C, Campbell G A, Whittaker A G et al. Elimination of transmissible spongiform encephalopathy infectivity and decontamination of surgical instruments by using radio-frequency gas-plasma treatment. J Gen Viro/ 2005; 86: 2393-2399.

38. British Dental Association. Infection control in dentistry. Advice Sheet A12. 2002. www.bda.org (accessed 23 April 2007)

39. Bagg J, Sweeney C, Roy K M, Sharp T, Smith A. Cross infection control measures and the treatment of patients at risk of Creutzfeldt-Jakob disease in UK general dental practice. Br Dent $J$ 2001; 191: 87-90.

40. Lowe A H, Bagg J, Burke F J, MacKenzie D, McHugh S. A study of blood contamination of Siqveland matrix bands. Br Dent J 2002; 192: 43-45.

41. Lowe A H, Burke FJ, McHugh S, Bagg J. A survey of the use of matrix bands and their decontamination in general dental practice. Br Dent J 2002; 192: 40-42.

42. Messer H, Parashos P. Should endodontic files be single-use only? Aust Endod J 2003: 29: 143-145.

43. Miller C H, Riggen S D, Sheldrake M A, Neeb J M. Presence of microorganisms in used ultrasonic cleaning solutions. Am J Dent 1993; 6: 27-31.

44. Sanford J E. Cleaning with ultrasonics. American Machinist 1966; 110: 87-98.

45. Burkhart N W, Crawford J. Critical steps in instrument cleaning: removing debris after sonication. J Am Dent Assoc 1997; 128: 456-463.

46. NHS Scotland. Sterile Services Provision Review Group: 1st Report (The Glennie Framework). 2002. http://www.scotland.gov.uk/library3/health/sspr. pdf (accessed 23 April 2007)

47. Weightman N C, Lines L D. Problems with the decontamination of dental handpieces and other intra-oral dental equipment in hospitals. J Hosp Infect 2004; 56: 1-5.

48. Washer disinfectors. Health Technical Memorandum (HTMO) 2030. London: NHS Estates, 1997.

49. Ritchlinie 93/92 EWG des Rates vom 14. uber Medizinprodukte. 1993

50. A protocol for the local decontamination of surgical instruments. London: NHS Estates, Department of Health, 2001. http://www.show.scot.nhs. uk/sehd/publications/sspr/sspr-14.htm (accessed 23 April 2007)

51. Bradley C R, Babb J R. Endoscope decontamination: automated vs. manual. J Hosp Infect 1995: 30 (Suppl): 537-442.

52. Martiny $H_{\text {, Floss } H}$, Zuhlsdorf $B$. The importance of cleaning for the overall results of processing endoscopes. J Hosp Infect 2004; 56 (Suppl): S16-S22.

53. Zuhlsdorf B, Emmrich M, Floss H, Martiny H. Cleaning efficacy of nine different cleaners in a washer-disinfector designed for flexible endoscopes. J Hosp Infect 2002; 52: 206-211.

54. Zuhlsdorf B, Floss H, Martiny H. Efficacy of 10 different cleaning processes in a washer-disinfector for flexible endoscopes. J Hosp Infect 2004: 56: 305-311.

55. Zuhlsdorf B, Winkler A, Dietze B, Floss H, Martiny $H$. Gastroscope processing in washer-disinfectors at three different temperatures.J Hosp Infect 2003; 55: 276-282.

56. Richards J, Spencer R, Fraise A et al. Rinse water for heat labile endoscopy equipment. J Hosp Infect 2002; 51: 7-16.

57. MacKay W G, Leanord A T, Williams C L. Water, water everywhere nor any a sterile drop to rinse your endoscope. J Hosp Infect 2002: 51: 256-261. 
58. Allen JI, Allen M O, Olson M M et al. Pseudomonas infection of the biliary system resulting from use of a contaminated endoscope. Gastroenterology 1987; 92: 759-763.

59. Alvarado C J, Stolz S M, Maki D G. Nosocomial infections from contaminated endoscopes: a flawed automated endoscope washer. An investigation using molecular epidemiology. Am J Med 1991: 91: 272S-280S.

60. Whitworth C L, Davies K, Palmer N O, Martin M $V$. An investigation of the decontamination of Siqveland matrix bands. Br Dent J 2007; 202: E12

61. Stansfield S. Plasma etching fundamentals and applications. In Series on Semiconductor Science and Technology. Oxford: Oxford University Press, 1998.

62. Whittaker A G, Graham E M, Baxter R L et al. Plasma cleaning of dental instruments. J Hosp Infect 2004; 56: 37-41.

63. Birmingham J G, Hammerstrom D J. Bacterial decontamination using ambient pressure non thermal discharges. IEEE Trans Plasma Sci 2000 ; 28: 41-50.

64. Herrmann H W, Henins I, Park J, Selwyn G. Decontamination of chemical and biological warfare (CBW) agents using an atmospheric pressure plasma jet (APPJ). Physics of Plasmas 1999 6: 2284-2289.

65. Baier R E, Carter J M, Sorensen S E et al. Radiofrequency gas plasma (glow discharge) disinfection of dental operative instruments, including handpieces. J Oral Implantol 1992; 18: 236-242.

66. Bialasiewicz A A, Fortsch M, Sammann A, Draeger J. Plasma sterilization of selected ophthalmic instruments for combined intraocular surgery. Ophthalmic Res 1995; 27 (Suppl) 1: 124-127.
67. Ayliffe G. Decontamination of minimally invasive surgical endoscopes and accessories. J Hosp Infect 2000; 45: 263-277.

68. von Woedtke T, Julich W D, Thal S et al. Antimicrobial efficacy and potential application of a newly developed plasmabased ultraviolet irradiation facility. J Hosp Infect 2003; 55: 204-211.

69. Baxter H C, Campbell G A, Richardson PR et al. Surgical instrument decontamination: efficacy of introducing argon:oxygen RF gas-Plasma cleaning step as part of a cleaning cycle for stainless steel instruments. IEEE Trans Plasma Sci 2006; 34: 1337-1344.

70. Rice R G, Farguhar J W, Bollyky L. Use of ozone in drinking water treatment. J Am Water Works Assoc 1981; 73: 44-57.

71. Echols J, Mayne S. Cooling tower management using ozone instead of multichemicals. ASHRAEJ 1990; 32: 34-38.

72. Videla H A, Viera M R, Guiamet PS. Using ozone to control biofilms. Mater Perform 1995; 34: 40-44.

73. Guzel-Seydim Z B, Greene A K, Seydim A C. Use of ozone in the food industry. Lebensm Wiss Technol 2006: 37: 453-460.

74. Fetner R H, Ingols R S. A comparison of the bactericidal activity of ozone and chlorine against Escherichia coliat 1 degree. J Gen Microbiol 1956; 15: 381-385.

75. Foegeding P M. Ozone inactivation of Bacillus and Clostridium spore populations and the importance of the spore coat to resistance. Food Microbiol 1985; 2: 123-134.

76. Ishizaki K, Shinriki N, Matsuyama H. Inactivation of Bacillus spores by gaseous ozone. J App/ Bacteriol 1986; 60: 67-72.

77. Restaino L, Frampton E W, Hemphill J B, Palnikar P. Efficacy of ozonated water against various food-related microorganisms. Appl Environ Microbiol 1995: 61: 3471-3475.

78. Dufresne S, Hewitt A, S R. Ozone sterilisation: another option for healthcare in the 21st Century. Am J Infect Contro/ 2004; 32: E26-E27.

79. McLeod A H, Murdoch H, Dickinson J et al. Proteolytic inactivation of the bovine spongiform encephalopathy agent. Biochem Biophys Res Commun 2004; 317: 1165-1170.

80. Lemmer K, Mielke M, Pauli G, Beekes M. Decontamination of surgical instruments from prion proteins: in vitro studies on the detachment, destabilization and degradation of PrPSc bound to steel surfaces. J Gen Viro/ 2004; 85: 3805-3816.

81. Medical Devices Agency. Single-use medical devices: implications and consequences of re-use: MDA DB 2000 (04), 2000. http://www.dhsspsni.gov. uk/hea-db(ni)2000-4.pdf (accessed 23 April 2007)

82. Risk Assessment for VCJD and Dentistry. Economics and Operational Research Division. London: Department of Health, 2003. http://www.dh.gov. uk/PublicationsAndStatistics/Publications/PublicationsPolicyAndGuidance/PublicationsPolicyAndGuidanceArticle/fs/en?CONTENT_ID $=408$ 4662\&tchk=twiXsY (accessed 23 April 2007)

83. Haikel $Y$, Serfaty $R$, Bleicher $P$, Lwin T T, Allemann C. Effects of cleaning, disinfection, and sterilization procedures on the cutting efficiency of endodontic files. J Endod 1996; 22: 657-661.

84. Laurenson I F, Whyte A S, Fox C, Babb J R. Contaminated surgical instruments and variant CreutzfeldtJakob disease. Lancet 1999; 354: 1823.

85. Chu N S, McAlister D, Antonoplos P A. Natural bioburden levels detected on flexiblegastrointestinal endoscopes after clinical use and manual cleaning. Gastrointest Endosc 1998; 48: 137-142. 